\title{
Progress in molecular diversity of tonghaosu and its analogs
}

\author{
Biao-Lin Yin, Jun-Fa Fan, Yang Gao, Yu-Lin Wu* \\ State Key Laboratory of Bio-organic \& Natural Products Chemistry \\ Shanghai Institute of Organic Chemistry, Chinese Academy of Sciences \\ 354 Fenglin Road, Shanghai 200032 \\ E-mail:ylwu@pub.sioc.ac.cn
}

\section{Dedicated to Prof. Zhi-Tang Huang on the occasion of his 75th birthday, and in recognition of his contributions to organic chemistry}

(received 29 Nov 02; accepted 20 Jan 03; published on the web 28 Jan 03)

\begin{abstract}
This article summarizes our work on the synthesis of naturally occurring antifeeding compound tonghaosu containing spiroketal-enol ether unit and its analogs as well as their chemical properties with emphases on acid catalyzed nucleophilic additions, isomerization, selective reduction of the endo-cyclic double bond and selective oxidation of exo-cyclic double bond.
\end{abstract}

Keywords: Tonghaosu, spiroketal-enol ether, isomerization, nucleophilic addition, selective reduction, selective oxidation

\section{Introduction}

Tonghao (Chrysanthemum segetum L.) with specific odor is a very common vegetable in southern China during spring and autumn, and usually immune to the attack of insects. From it essential oil we identified an highly unsaturated spiroketal enol compound, 2-(2,4-hexadiynylidene)-1,6-dioxaspiro[4,4]-non-3-ene 1, as a $\mathrm{Z} / \mathrm{E}$ mixture, ${ }^{1}$ which has proved to be responsible for the antifeeding activity of tonghao and was named as tonghaosu in our laboratory. This compound together with its analogs $\mathbf{2}, \mathbf{3}$, and $\mathbf{4}$ (Figure 1) once was isolated from a similar plant Chrysanthemum coronarium 1 . and other plants of tribe Athemdeae, ${ }^{2}$ and more recently Chen reported the isolation of $\mathbf{2}$ from Dendranthema indicum Var. aromatic in Chinese Shengnongjia region. ${ }^{3}$ Compound 1 has been shown to have antifeeding activity toward silkworm, ${ }^{4 a}$ and its E-isomer exhibited spasmolytic and antiphlogistic properties. ${ }^{4 \mathrm{~b}, 4 \mathrm{c}}$ 


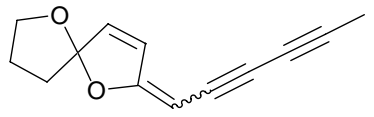

1

tonghaosu

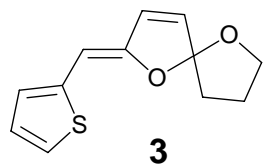

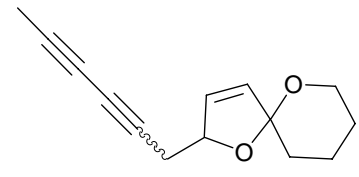

2

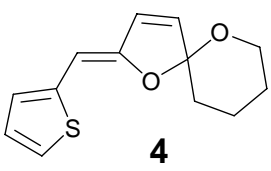

Figure 1

Spiroketals are present in many naturally occurring substances with biological interest, such as insect pheromones, antifeedants and polyether antibiotics, and a wide variety of synthetic strategies have been developed for this functionality. ${ }^{5}$ However most of the existing methodologies are not very suitable for spiroketal-enol ether found in tonghaosu 1. In the early 1960s, Bohlmann reported a 5-step approach to tonghaosu, but the overall yield of their route was quite low. ${ }^{6}$ Recently Y. Q. Tu ${ }^{7 a}$ and $\mathrm{H}$. Toshima ${ }^{7 \mathrm{~b}}$ have also mentioned the synthesis of tonghaosu, but neither of them has reached the end product.

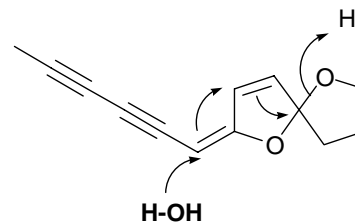

1-E

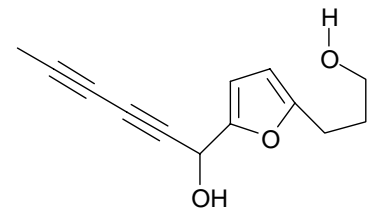

5

Scheme 1. Equilibrium between the Z- and E-isomer of 1.

During the isolation of tonghaosu 1, we noticed that in the presence of acid and trace amounts of water (or during silica gel chromatography or even in aged deuterated chloroform in an NMR tube) the E- and Z- isomers were in equilibrium with each other and furandiol 5 was supposed to be the intermediate. This observation prompted us to develop a synthetic strategy involving a furandiol as the key intermediate, the acid-catalyzed dehydration-spiroketalization as the key step and the readily available 2-furaldehyde or its derivatives as the starting material. And it was conceivable this strategy would enable us to vary the both sides of the dihyrofuran ring (A ring) of tonghaosu and hence a diverse collection of tonghaosu analogs could be obtained, which then would be a useful molecular library for researching for agrochemical leads (Scheme 2). 


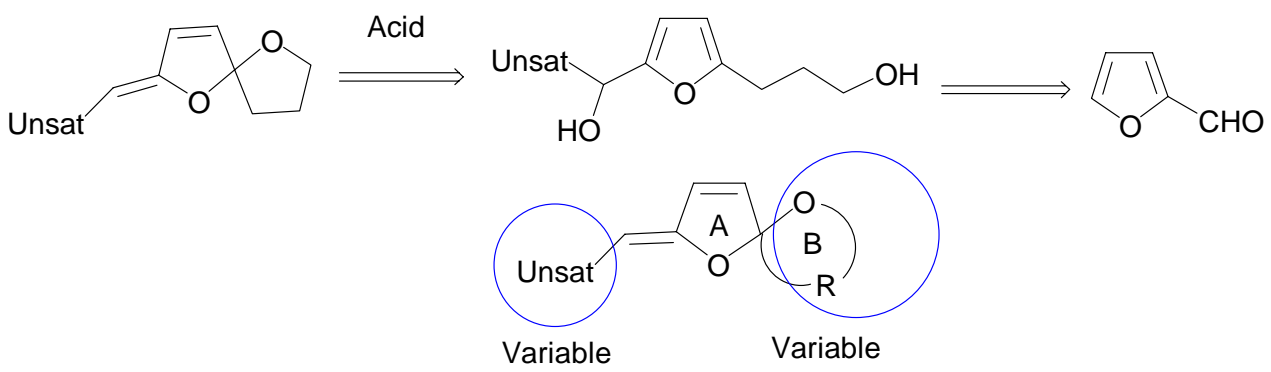

\section{Scheme 2}

\section{Syntheses of tonghaosu and its analogs}

\subsection{Syntheses of natural compounds 1-4, as well as left segment modified analogs}

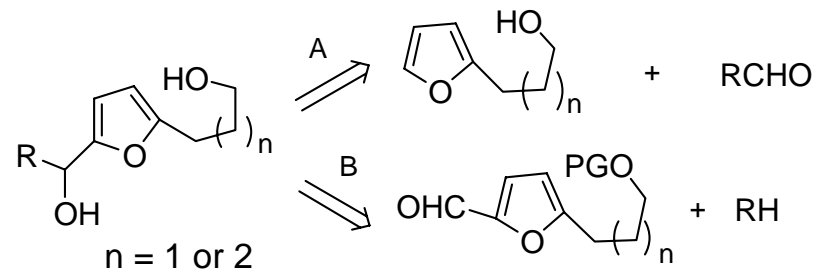

\section{Scheme 3}

With the above mentioned strategy in mind, we set out to synthesize natural products, 1-4, and the common key intermediate furandiol was envisaged to be built by coupling reaction of a organolithium reagent and an aldehyde as shown by the retrosynthetic analysis (scheme 3). The syntheses of $\mathbf{3}$ and $\mathbf{4}$ were first attempted, thus 3-(2-furyl)-propan-1-ol 6a and 4-(2-furyl)-butyl-1-ol 6b, prepared from furaldehyde according to known procedure, ${ }^{8}$ were treated with butyllithium and then 2-thiophenecarboxaldehyde to give furandiols $\mathbf{7 a}$ and $\mathbf{7 b}$, respectively, in good yields (route A, scheme 3). As expected, the latter two compounds could be converted to $\mathbf{3}$ and $\mathbf{4}$, respectively, in the presence of catalytic amounts of acid. And Lewis acid $\mathrm{CuSO}_{4} \cdot 5 \mathrm{H}_{2} \mathrm{O}$ proved to be the choice of catalyst with toluene as the solvent at $70{ }^{\circ} \mathrm{C}$, under which $\mathbf{3}$ and $\mathbf{4}$ could be obtained in excellent yields and only in the z-forms (Scheme 4).

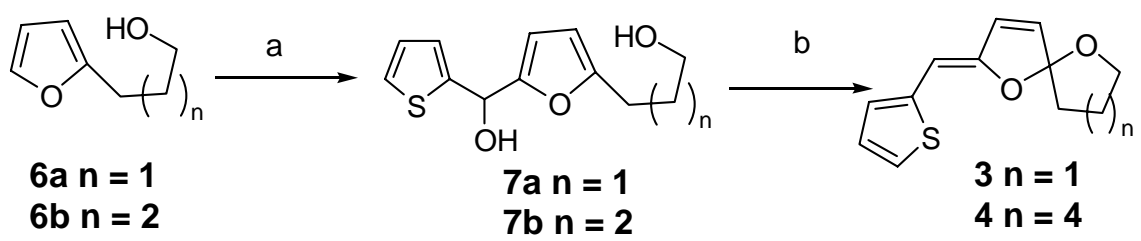

Scheme 4. Reagents and conditions: a) n-BuLi, TMEDA, THF, $0{ }^{\circ} \mathrm{C}-r t$, then 2-thiophenecarboxaldehyde, $-78{ }^{\circ} \mathrm{C}$-rt, $77 \%$ for $7 \mathbf{a}, 71 \%$ for $7 \mathbf{b}$; b) $\mathrm{CuSO}_{4} \cdot 5 \mathrm{H}_{2} \mathrm{O}$, toluene, $70{ }^{\circ} \mathrm{C}$, $97 \%$ for both 3 and 4. 
In the course of synthesis $\mathbf{1}$ and $\mathbf{2}$, we also attempted to adopt route A to prepare the corresponding furandiols, because it seemed more convergent than route B. Unfortunately, it soon turned out that the 2,4-diyne-hexaldehyde, a component for the coupling reaction, was unstable under the strongly basic condition. This made us to explore route B. Thus protection of $\mathbf{6}$ as acetates followed by Vilsmeier-Haack formylation afforded furan aldehydes 8, which reacted with lithium acetylide derived from penta-1,3-diyne to provide $\mathbf{9 a}$ and $\mathbf{9 b}$ in 75\% and 69\% yields respectively. Subsequent deacetylation and $\mathrm{CuSO}_{4} \cdot 5 \mathrm{H}_{2} \mathrm{O}$ catalyzed spiroketalization gave $\mathbf{1}$ and $\mathbf{2}$ in high yields respectively (Scheme 5). ${ }^{9}$

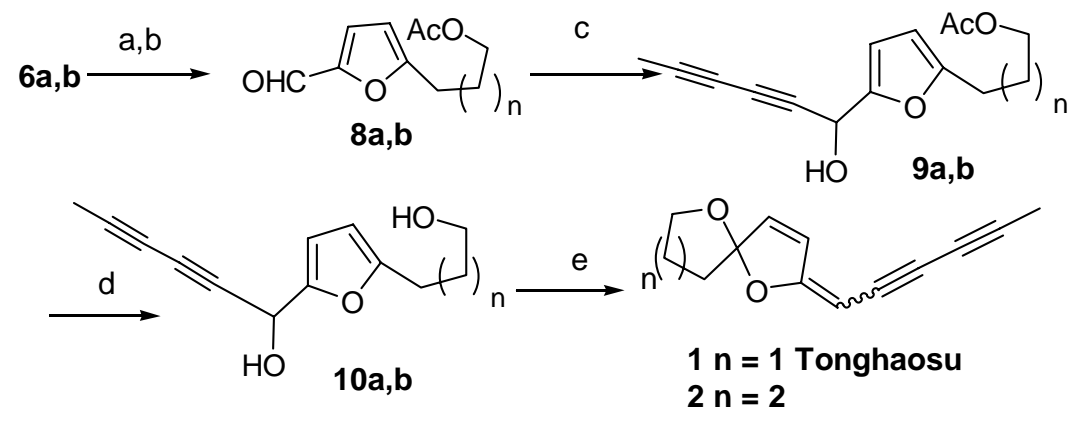

Scheme 5. Reagents and conditions: a) $\mathrm{Ac}_{2} \mathrm{O}$, Py, DMAP, 91\%; b) DMF, $\mathrm{POCl}_{3}, \mathrm{CH}_{2} \mathrm{Cl}_{2}, 91 \%$; c) 1,3-Pentadiyne, BuLi, THF, $-78{ }^{\circ} \mathrm{C}$-rt; d) $\mathrm{KHCO}_{3}, \mathrm{MeOH} / \mathrm{H}_{2} \mathrm{O}$; e) $\mathrm{CuSO}_{4} \cdot 5 \mathrm{H}_{2} \mathrm{O}$, toluene, $70{ }^{\circ} \mathrm{C}, 94 \%$ for 3 and $92 \%$ for 4 .

Thus the total syntheses of naturally occurring compounds 1-4 were accomplished in an efficient and practical manner, and in a similar way we also prepared a variety of left side modified analogs, some of which are shown in Figure 2. And it is worth noting that when the unsaturated part (left side) of the compound is an aromatic ring, it is a stereomerically pure compound (only $\mathrm{Z}$ isomer), however if the unsaturated part is an acyclic side chain, a Z, E mixture is formed, such as tonghaosu 1, 2 and 11j-k. ${ }^{9,10}$.

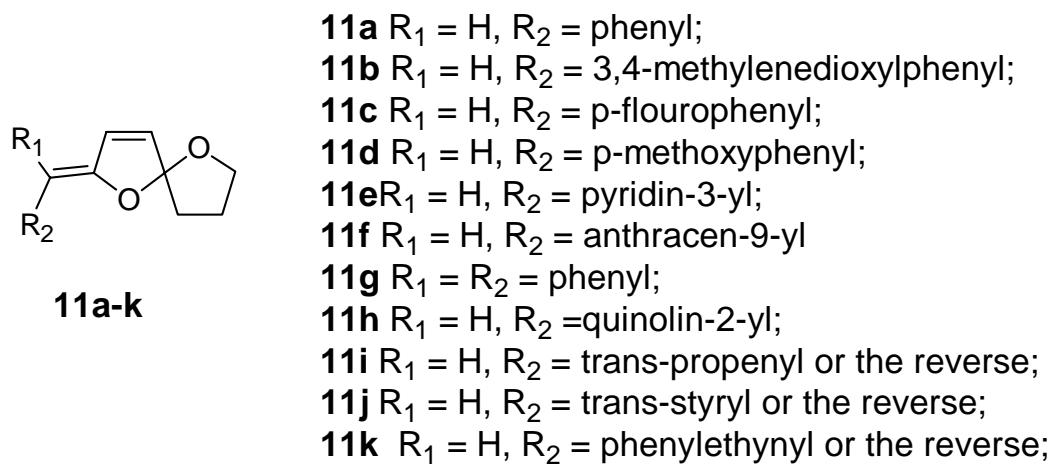

Figure 2. Some of the left side modified analogs. 


\subsection{Synthesis of both-sides modified analogs}

Using furan-2-yl-methanol as the starting material, we prepared a series of 1,6,9-trioxaspiro[4,5]dec-3-enes 14. Given that heterocycles might play a role in biological activity, nitrogen-containing heterocycles, such as pyrazole, pyridine and imidazole, were introduced into the left sides of some analogs (Scheme 6). And indeed these analogs have shown significant antifeeding activity in preliminary biological tests. ${ }^{11,12}$
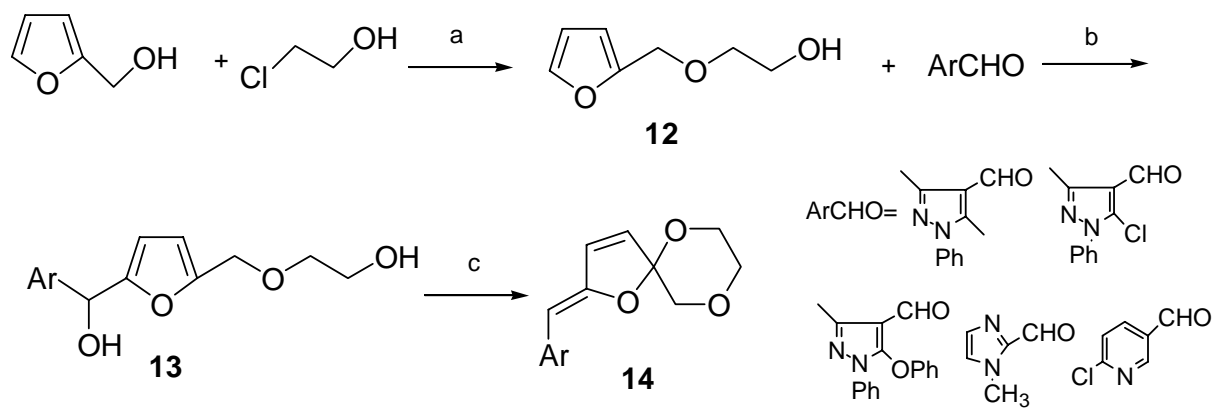

Scheme 6. Reagents and conditions: a) $50 \% \mathrm{NaOH}$, THF $/ \mathrm{H}_{2} \mathrm{O}, \mathrm{Bu}_{4} \mathrm{NBr}, 70 \%$; b) n-BuLi, THF, -78 , then $\mathrm{ArCHO}, 70 \sim 80 \%$; c) $\mathrm{CuSO}_{4} \cdot 5 \mathrm{H}_{2} \mathrm{O}$, toluene, $70{ }^{\circ} \mathrm{C}$, $>90 \%$.

As we see from the above, the coupling reaction between furanyllithium and an aldehyde was utilized to prepare most of the key intermediates furandiols. Although the yield for this step was good, the air and moisture sensitive reagent, butyllithium, had to be used, which made it inconvenient and uneconomical to scale up this reaction. So an alternative was established for this purpose, which employed Freidel-Crafts benzoylation to form a diarylketone 15, and reduction of the latter with $\mathrm{NaBH}_{4}$ followed by treatment with potassium carbonate (Scheme 7). ${ }^{13}$

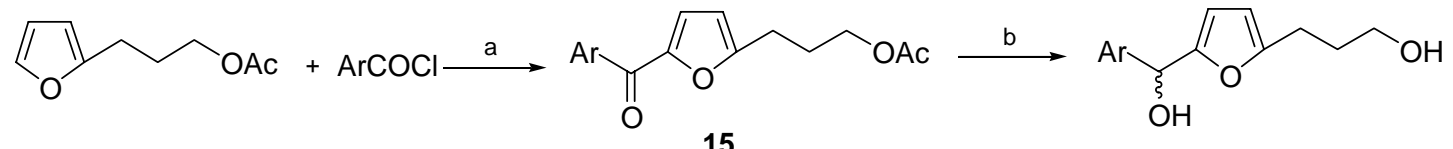

Scheme 7. Reagents and conditions: a, $\mathrm{ZnCl}_{2}, \mathrm{ClCH}_{2} \mathrm{CH}_{2} \mathrm{Cl}$, reflux; b, $\mathrm{NaBH}_{4}, \mathrm{EtOH}$, rt, then, $\mathrm{K}_{2} \mathrm{CO}_{3}$, $\mathrm{H}_{2} \mathrm{O}$, rt.

By use of the Freidel-Crafts benzoylation reaction, we easily obtained another kind of tonghaosu analog 19, which contained an amide functionality in the right side (B ring). Its synthesis was started from methyl furancarboxylate. Bezoylation gave ketone ester 16, which reacted with $N$-ethyl 2-aminoethanol in refluxed methanol to afford amide $\mathbf{1 7}$. Selective reduction of the latter with sodium borohydride led to furandiol 18, a spiroketaliztion precursor bearing amide at the right side chain, which then was converted smoothly to compound 19 upon treatment with $\mathrm{CuSO}_{4} \cdot 5 \mathrm{H}_{2} \mathrm{O}$ (Scheme 8). ${ }^{14}$ 


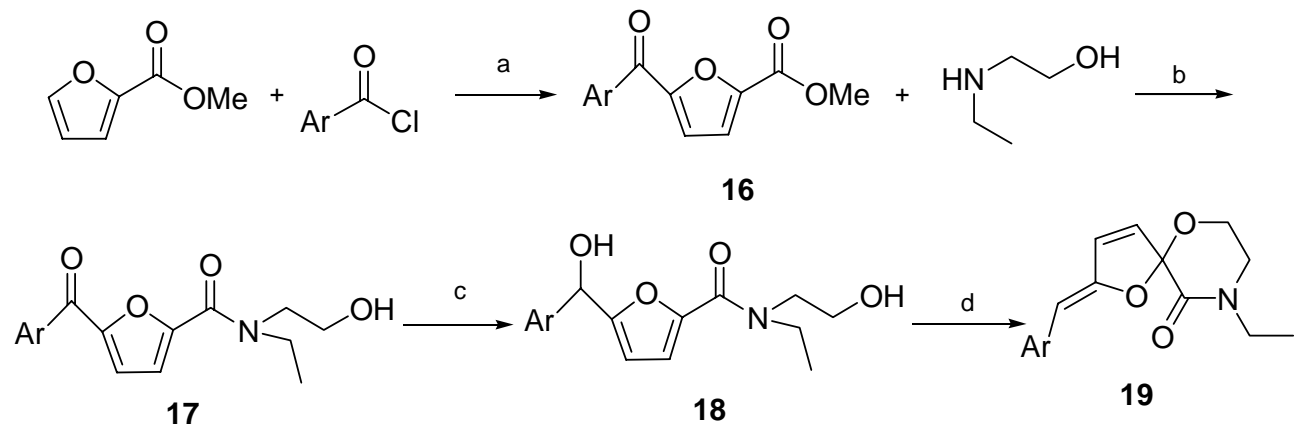

Scheme 8. Reagents and conditions: a, $\mathrm{FeCl}_{3}, \mathrm{ClCH}_{2} \mathrm{CH}_{2} \mathrm{Cl}$, reflux, 2h; b, $\mathrm{MeOH}$, reflux, 12h; c, $\mathrm{NaBH}_{4}, \mathrm{MeOH}$, rt; d, $\mathrm{CuSO}_{4} \cdot 5 \mathrm{H}_{2} \mathrm{O}$.

On the other hand, a series of very interesting compounds $\mathbf{2 0}$ containing ketal-spiroketal enol ether unit were also prepared from $\mathbf{1 6}$ in only two steps, by reduction with $\mathrm{LiAlH}_{4}$ as the reducing agent and the treatment of the resulting diol with dimethoxypropane in the presence of CSA (Scheme 9). ${ }^{14}$

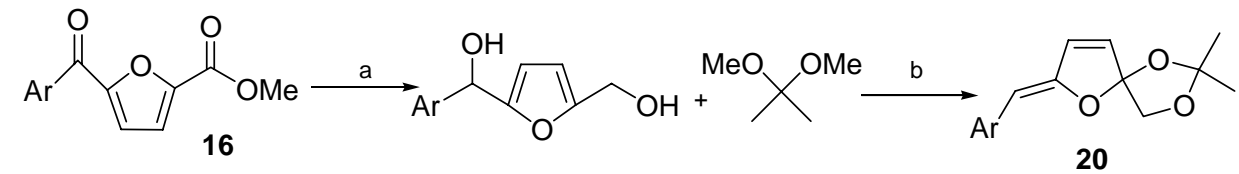

Scheme 9. Reagents and conditions: a, $\mathrm{LiAlH}_{4}$, THF; b, CSA, benzene.

\subsection{Synthesis of optically pure tonghaosu analogs}

In recent years, more and more enatiomerically pure compounds act as pharmaceuticals and agrochemicals and showed superiority to their corresponding mixtures. In order to investigate structure-activity relationships of tonghaosu and its analogs as well as methodology development, we devoted much effort on enantionselective synthesis of tonghaosu analogs. Because the conversion of furandiol to spiroketal could be achieved in the presence of catalytic amounts of Lewis acid, such as $\mathrm{CuSO}_{4} \cdot 5 \mathrm{H}_{2} \mathrm{O}$, we wondered if a chiral Lewis acid was used, then an enatiomerically pure tonghaosu analog would be formed. We thus chose titanium(IV) as the metal ion and screened lots of chiral ligands. Unfortunately the preliminary results were unsatisfactory and only up to a $20 \%$ ee value was obtained (Scheme 10). The poor results might be due to ring opening and closure of spiroketal enol ether unit, which would erode the established chirality.

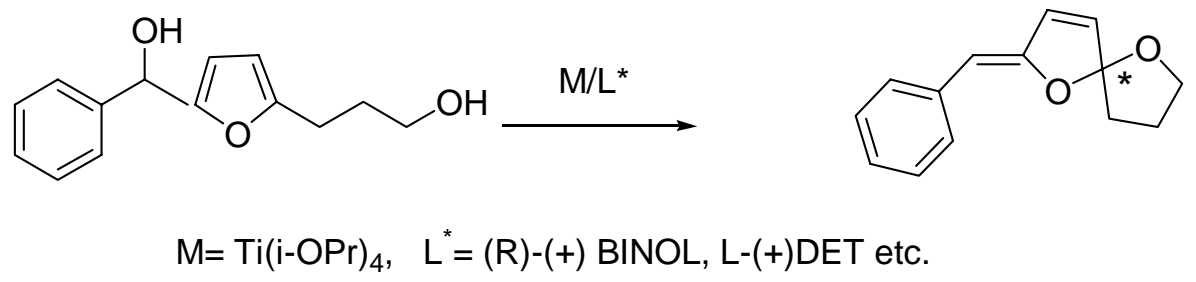




\section{Scheme 10}

Besides the above mentioned reagent-controlled reaction, we also explored substrate-based control to prepare optically pure tonghaosu analogs. Initial effort was devoted to preparing a tonghaosu analog precursor with a chiral center next to the furan ring. As shown in Scheme 11, $R$-2,2-dimethyl-[1,3]dioxolane-4-carbaldehyde derived from D-mannitol was used as the chiral building block and two chiral centers were introduced into the right side chain of 21, which was treated with PPTS in toluene to afford 22 as a 3:1 mixture of diasteromers in favor of $S$ configuration at the newly formed chiral center. ${ }^{14}$
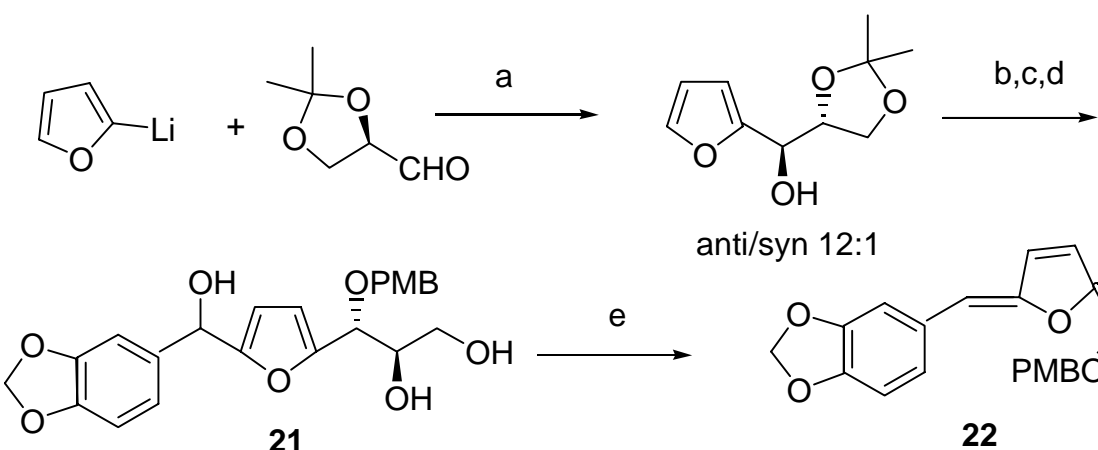

anti/syn 12:1

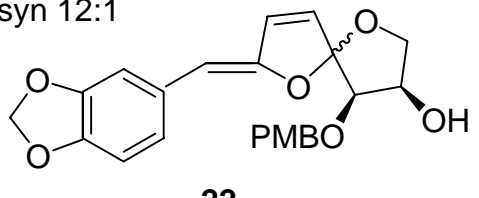

22

Scheme 11. Reaction conditions: a, $\mathrm{ZnBr}_{2}$, THF, 72\%; b), $\mathrm{NaH}, \mathrm{DMF}, \mathrm{PMBCl}, \mathrm{KI}, 96 \%$; ). $\mathrm{MeOH}$, PPTS, reflux, 72\%; d), n-BuLi, TMEDA, piperonal, 30\%; e), PPTS, toluene, 76\%.

Two amide containing compounds, 23 and 26, generated according to the procedure outlined in Scheme 8, were also examined as the ketalization precursors. Under optimized condition, with CSA as the catalyst in methylene chloride at room temperature, $\mathbf{2 3}$ could lead to a mixture of $\mathbf{2 4}$ and $\mathbf{2 5}$, with ratio greater than 8:1. More promisingly, 26 afforded a diastereomerically pure compound 27. Both the configurations of $\mathbf{2 4}$ and 27, as shown in Scheme 12, were determined unambiguously by X-ray analysis. ${ }^{14,15}$

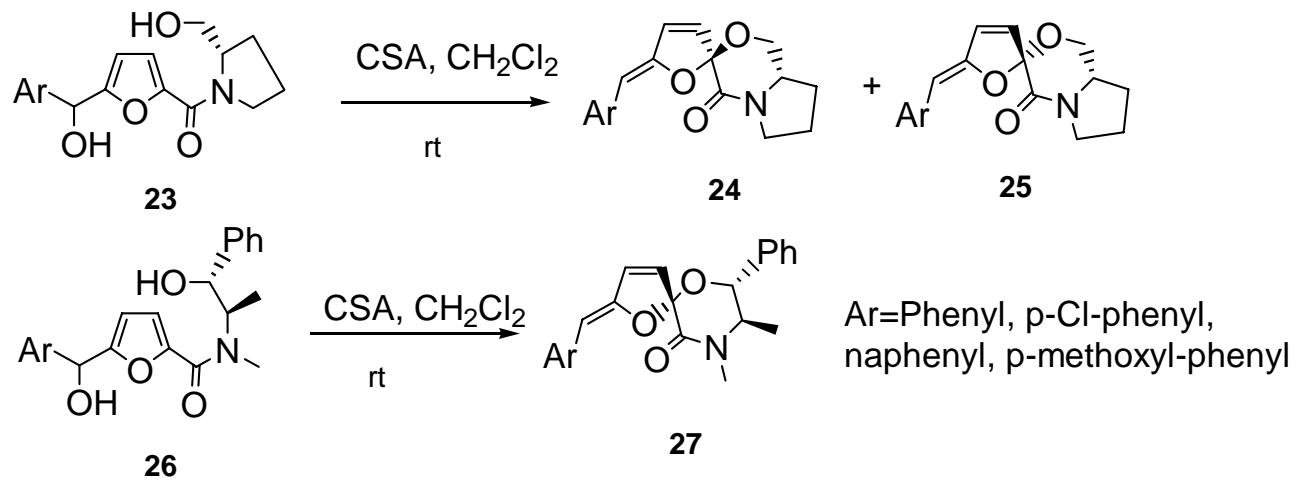

\section{Scheme 12}




\section{Reactions of tonghaosu analogs}

Inspection of the spiroketal enol ether segment of tonghaosu analogs reveals that there exist five reactive sites as shown with arrows in Figure 3. How to distinguish their reactivity from each other is a challenging task and will open another door for the molecular diversity of tonghaosu analogs and derivatives in a similar way as the molecular diversity from heterocyclic ketene aminals reported by Prof. Zhi-Tang Wang. ${ }^{16}$ We calculated the net charges of the five carbons and two oxygens of the spiroketal enol ether unit in compound 11a with semi-empirical method (AM1), the data were shown in Table 1.

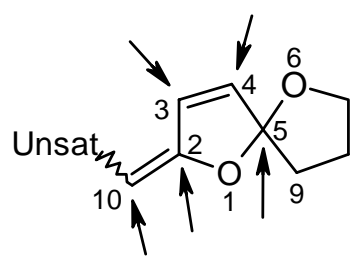

28

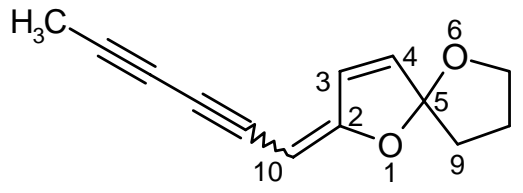

1 (Tonghaosu)

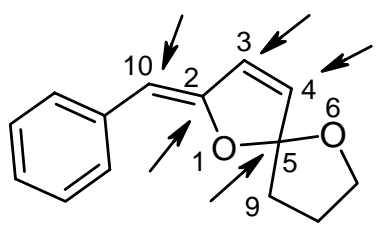

$11 \mathrm{a}$

Figure 3

Table 1. The net charges of spiroketal enol-ether segment of compound 11a

\begin{tabular}{c|ll|l|l} 
O-1 - -0.224451 & C-2 0.049685 & C-3 -0.127253 & C-4 -0.172121 \\
\hline C-5 0.202139 & O-6 -0.257257 & C-10 -0.149155 &
\end{tabular}

\subsection{Acid catalyzed nucleophilic reactions with mercaptans and alcohols}

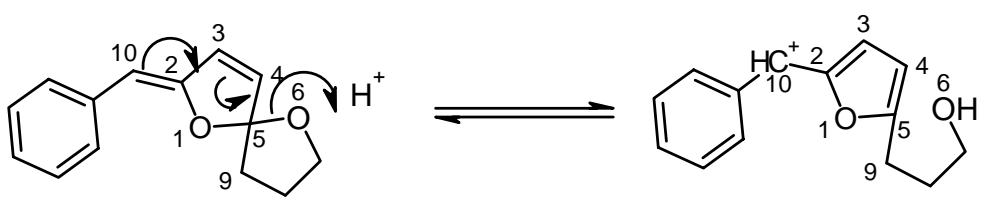

Figure 4. The equilibrium between spiroketal enolether form and furan form.

From Table 1 we can see that O-6 has more negative charge than O-1 and at low temperature Lewis acid or protonic acid will firstly interact with O-6, and an equilibrium between spiroketal enol ether form and furan form will take place. (Figure 4) Thereafter, the nucleophilic reagent will firstly attack the carbon-10, $\beta$ position of the enol ether. As expected, derivatives $\mathbf{2 9}$ and $\mathbf{3 0}$ were obtained from the reactions of tonghaosu analogs with alcohols and mercaptans, respectively, in the presence of acid (Scheme 13). However the alcohols were limited to methanol and ethanol, no reaction was observed for other higher homologues. In the case of mercaptans, acids other than $\mathrm{FeSO}_{4}$ were also effective in catalyzing the reaction. ${ }^{17}$ 

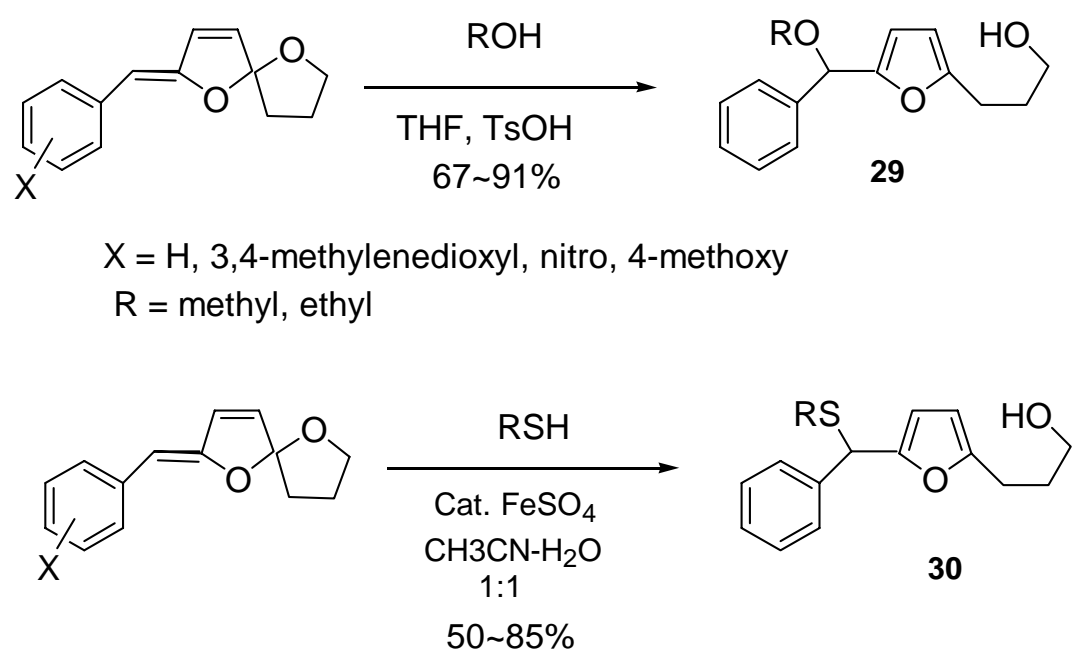

$\mathrm{X}=\mathrm{H}, 3,4$-methylenedioxyl, 4-methoxy

$\mathrm{RSH}=$ Benzyl thiol, L-cysteine, L-glutathione

\section{Scheme 13}

\subsection{Lewis acid mediated C-C bond formation}

Grignard reagents were also tested as the nucleophiles. As illustrated in scheme 14, ethylmagnesium bromide would attack two sites of 31, one at $\beta$ position (C10) of the enol ether, the other at the spiro-carbon (C5), to give a ca 1.3:1 mixture of $\mathbf{3 2}$ and $\mathbf{3 3}$ in moderate yield. However in the case of phenylmagnesium bromide, $\mathbf{3 3}$ from attack at $\mathrm{C} 5$ was the only product. It should be pointed out that the presence of $\mathrm{BF}_{3} \cdot \mathrm{OEt}_{2}$ was crucial to the reaction, otherwise it would be very sluggish. The substituent on the phenyl ring seemed to make no difference. ${ }^{17}$
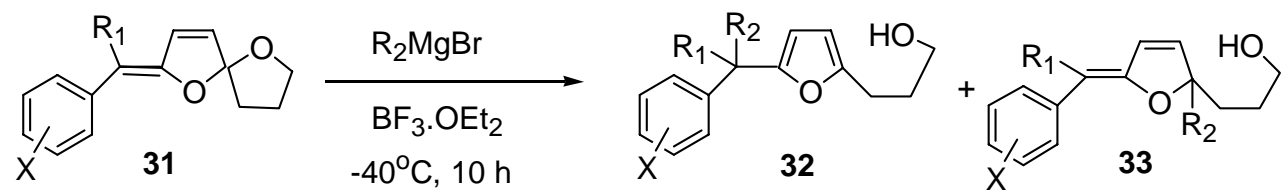

$$
\begin{aligned}
& \mathrm{X}=\mathrm{H}, \mathrm{R}_{1}=\mathrm{H}, \mathrm{R}_{2}=\mathrm{Et} \\
& X=3,4-\text { methylenedioxyl, } \mathrm{R}_{1}=\mathrm{H}, \mathrm{R}_{2}=\mathrm{Et} \\
& X=4-\mathrm{CH}_{3} \mathrm{O}, \mathrm{R}_{1}=\mathrm{H}, \mathrm{R}_{2}=\mathrm{Et} \\
& \mathrm{X}=\mathrm{H}, \mathrm{R}_{1}=\mathrm{H}, \mathrm{R}_{2}=\mathrm{Ph} \\
& X=3,4 \text {-methylenedioxyl, } R_{1}=H, R_{2}=P h \\
& X=H, R_{1}=P h, R_{2}=P h
\end{aligned}
$$

$$
\begin{gathered}
\mathbf{3 2} \mathbf{a}=38 \%, \mathbf{3 3} \mathbf{a}=27 \% \\
\mathbf{3 2} \mathbf{b}=39 \%, \mathbf{3 3} \mathbf{b}=31 \% \\
\mathbf{3 2} \mathbf{c}=36 \%, \mathbf{3 3} \mathbf{c}=30 \% \\
\mathbf{3 2} \mathbf{d}=0 \%, \mathbf{3 3} \mathbf{d}=67 \% \\
\mathbf{3 2} \mathbf{e}=0 \%, \mathbf{3 3 e}=64 \% \\
\mathbf{3 2} \mathbf{f}=0 \%, \mathbf{3 3} \mathbf{f}=59 \%
\end{gathered}
$$

\section{Scheme 14}

Interestingly, treatment of thiophene substituted tonghaosu analogs 3 and 4 with $\mathrm{BF}_{3} \cdot \mathrm{Et}_{2} \mathrm{O}$ afforded dimers 34 and 35 in 44 and 50\% yield respectively (Scheme 15). The latter two were naturally occurring compounds isolated by Hofer et al. from ludoviciana in $1988 .{ }^{18}$ 
2

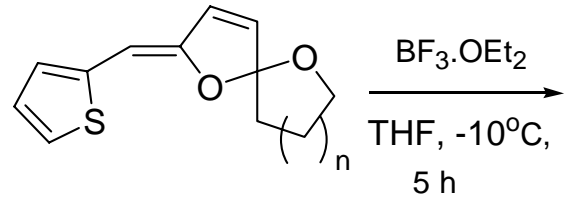

$$
3 \mathrm{n}=1
$$$$
4 n=2
$$

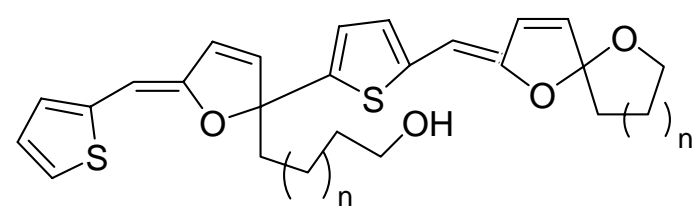

$\mathrm{n}=1, \quad 34$

$\mathrm{n}=2, \quad 35$

\section{Scheme 15}

\subsection{Base catalyzed hydroamination}

Contrast to the above two addition reactions, lithium amide, prepared from $n$-butyllithium and excess of amine, attacked instead the endo-double bond of the tonghaosu analogs with high regioselectivity. Compound 36 from attack at the C-4 position was the predominant product, where the incoming amino group was syn to O-6 presumably due to the chelating effect of this oxygen, and its stereochemistry was determined by x-ray analysis (Scheme 16). ${ }^{19}$

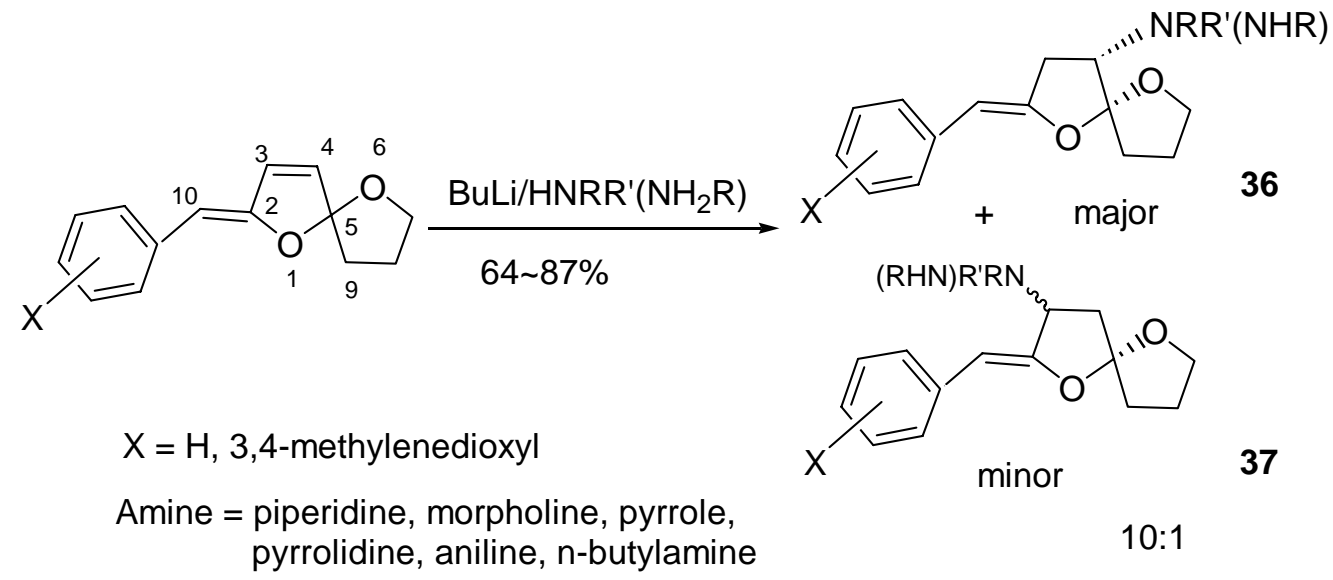

\section{Scheme 16}

\subsection{Acid catalyzed isomerization with skeletal change}

Our synthesis of tonghaosu analogs was based on the Brønsted or Lewis acid catalyzed dehydration-spiroketalization of corresponding furandiols in an aprotic aromatic solvent such as toluene. ${ }^{9}$ However, if a synthesized tonghaosu analog, such as compound 11a, was refluxed with a catalytic amount of $\mathrm{ZnCl}_{2}$ in aqueous ethylene glycol dimethyl ether, a new compound with the same molecular weight was smoothly formed in $83 \%$ yield. Spectroscopic data (IR, NMR, MS) showed that it was definitely a cyclopentenone derivative 38 (Scheme 17). Under the same reaction conditions other tonghaosu analogs gave similar cyclopentenone derivatives in 70 90 \% yields. ${ }^{20}$ 
<smiles>OCCCc1ccc(C(O)c2ccccc2)o1</smiles>
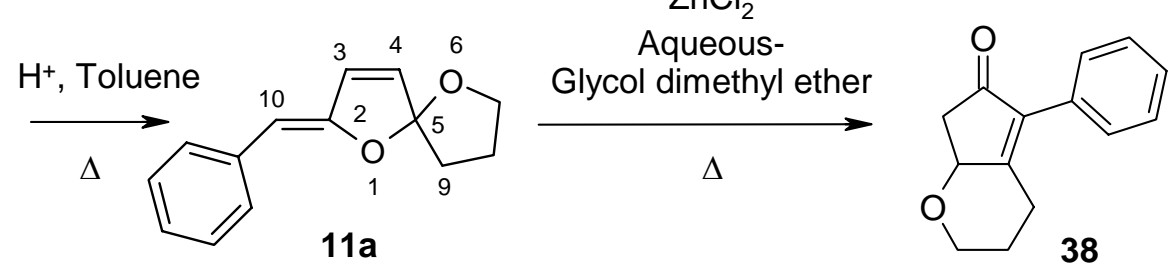

\section{Scheme 17}

With this method in our hands, we completed the first synthesis of a natural product chrycorin 39 which was isolated from Chrysanthemum coronarium by Tada and Chiba in 1984, ${ }^{4 a}$ and showed medium inhibitory activity toward the root growth of lettuce seedling. Thus tonghaosu thiophene analog 3 was treated with $\mathrm{ZnCl}_{2}$ in the same reaction conditions to give the desired compound 39 in $88 \%$ yield (Scheme 18). ${ }^{20}$ All the spectroscopic data were in accordance with that of the natural one.

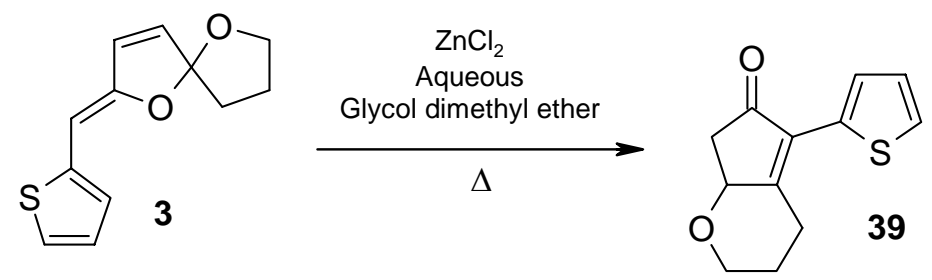

\section{Scheme 18}

The mechanism for this skeletal rearrangement may be as follows:
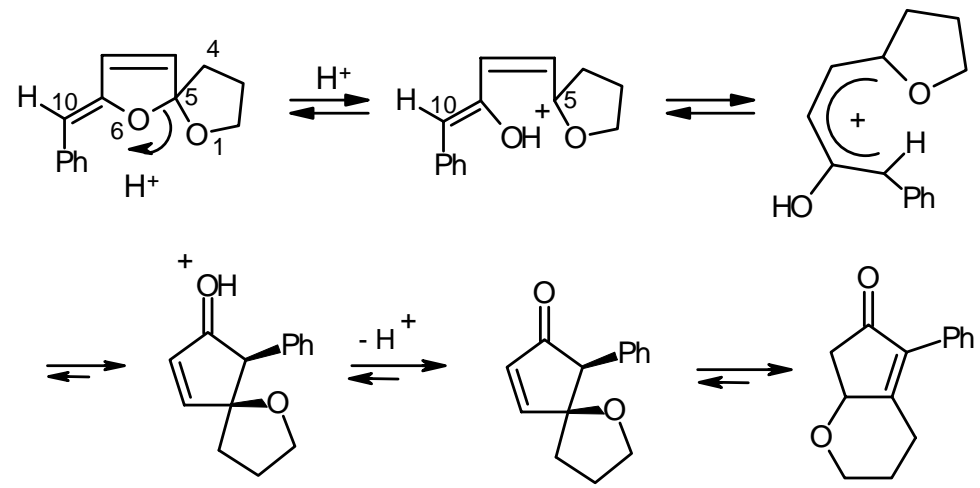

\section{Scheme 19}

2.5 Selective reduction of the endo-double bond and the acid catalyzed rearrangements of partial and full reduction products

We had tried the catalytic hydrogenation of tonghaosu analogs in the hope of getting selectively endo-double bond reduced product, which would keep the spiroketal enol unit necessary for the 
antifeeding activity, however it was very difficult to stop the hydrogenation process after one mole of hydrogen was absorbed. Later dimide was examined as the reducing agent and proved to be effective, albeit somewhat vigorous reaction conditions, DME at reflux for $12 \mathrm{~h}$, were needed. More recently, this selective reduction was realized under very mild conditions using sodium borohydride in the presence of catalytic amounts of nickel chloride, bismuth chloride or cobalt chloride (Scheme 20). ${ }^{21}$

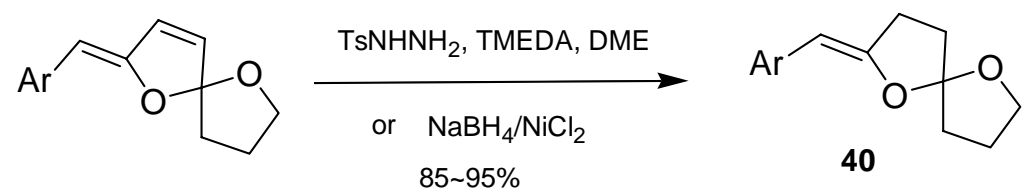

\section{Scheme 20}

The partial reduction products $\mathbf{4 0}$ could easily be converted to cyclopentenone derivatives $\mathbf{4 1}$ upon treatment with hydrochloric acid and then sodium hydroxide. However, treatment of compounds 42(obtained by palladium catalyzed hydrogenation) with hydrochloric acid in methanol or $\mathrm{BF}_{3} \cdot \mathrm{OEt}_{2}$ in THF afforded bezene-fused 8-oxabicyclo[3,2,1]octanes $\mathbf{4 3}$ as the only products in moderate to good yields (Scheme 21). ${ }^{22}$ This reaction is the first example of Fried-Craft alkylation using spiro-ketals as alkylating agents and provides a easy access to a subclass of bridged compounds with a tertiary carbon at the bridgehead.

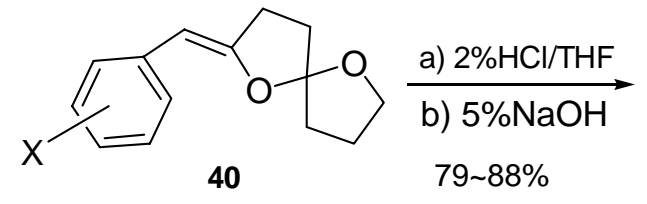

$\mathrm{X}=\mathrm{H}$, 3,4-methylenedioxyl, 4-methoxy, 5-methyl

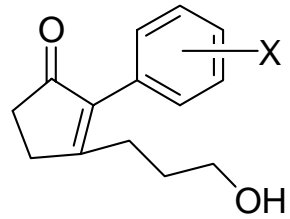

41

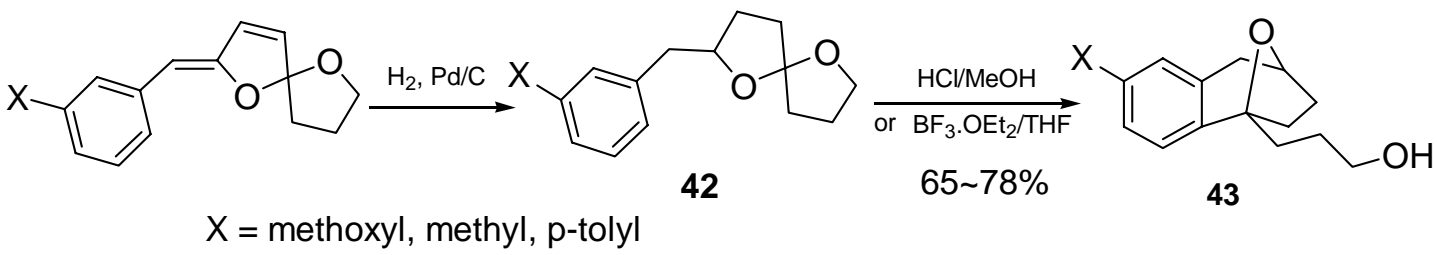

\section{Scheme 21}

\subsection{Selective oxidation of the exo-double bond}

In contrast to the selective reduction, the selective oxidation with MCPBA occurs at the exo-double bond, this may be rationalized by the fact that the $\beta$ position (C-10) of the enol ether has more electron density as shown in Table 1 . Thus oxidation of tonghaosu analogs with MCPBA in $\mathrm{THF}-\mathrm{H}_{2} \mathrm{O}$ at $0{ }^{\circ} \mathrm{C}$ followed by treatment with $p$-toulenesulfonic acid afforded compounds $\mathbf{4 4}$ containing spiroketal and enone functionalities (Scheme 22). ${ }^{23}$ These compounds would be very useful for further exploration. 


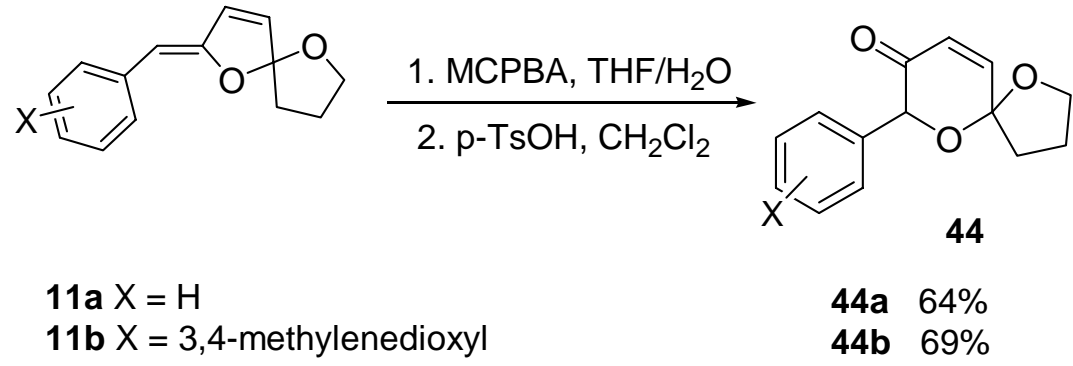

\section{Scheme 22}

\section{Summary}

Naturally occurring tonghaosu 1 with insect antifeeding activity and a wide variety of its analogs have been synthesized based on the acid-catalyzed dehydration- spiroketalization reaction developed by us. In addition, reactions of the analogs were thoroughly explored, which provided a functional and skeletal diversity of compounds. Thus the target-oriented synthesis accompanied with diversity-oriented synthesis enabled us to build a molecular library of tonghaosu and its analogs and derivatives.

\section{Acknowledgments}

This work was supported by the National Natural Science Foundation of China (Grant No. 29672083, 20072043), the Chinese Academy of Sciences, the State Ministry of Science and Technology (G2000077502) and the Shanghai Committee of Science and Technology.

\section{References}

1. Partial result has been published in: Wu, Z.-H.; Wang, J.; Li, J.-C.; X, Y.-Z.; Yu, A.-L.; Feng, Z.-R.; Shen, J.; Wu, Y.-L.; Guo, P.-F.; Wang, Y.-N. Natural Product R \& D [China] 1994, 6, 1.

2. (a) Hegnauer, R. in Chemotaxonomie der Pflanzen, Vol.3, Birkhauser Verlag, Basel, 1964, pp 447; (b) Bohlmann, F.; Burkhardt, T.; Zdero, C. Naturally Occurring Acetylenes, Academic Press, London, 1973 (c) H. Greger, in The Biology and Chemistry of Compositae (Eds.: Heywood, V. H.; Harborne J. B.; Turner, B. L.), chapter 32, Academic Press, London, 1977 (d) Bohlmann, F. in Chemistry and Biology of Naturally Occurring Acetylenes and Related Compounds (Eds.: Lam, J.; Bretler, H.; Anason, T.; Hansen, L.), Elsevier, Amsterdam, 1988, pp 1. (e) Zdero, C.; Bohlmann, F., Plant Syst. Evol. 1990, 171, 1. 
3. Chen, L., PhD Thesis, 2001, South China Agricultural University.

4. (a) Tada, M.; Chiba, K. Agric. Biol. Chem. 1984, 48, 1367. (b) Martinez, V.; Barbera, O.; Sanchez-Parareda, J. A. Phytochemistry 1987, 26, 2619. (c) Breinlich, J.; Scharmagel, K. Arznei,-Forsch. 1968, 18, 429.

5. Peeron, F.; Albizati, K. F. Chem. Rev. 1989, 89, 1617.

6. (a) Bohlmann, F.; Jastrow, H.; Ertringshausen, G.; Kramer, D. Chem. Ber. 1964, 97, 801. (b) Bohlmann, F.; Florentz, G., Chem. Ber. 1966, 99, 990.

7. (a) Tu, Y.-Q.; Byriel, K. A.; Kennard, C. H. L.; Ketching, W. J. Chem. Soc. Perkin Trans. 1 1995, 1309. (b) Toshima, H.; Furumoto, Y.; Inamura, S.; Ichihara, A., Tetrahedron Lett. 1996, 5707.

8. Taylor, D. A. H. J. Chem. Soc. 1959, 2767.

9. (a) Gao, Y.; Wu, W.-L.; Ye, B.; Zhou, R.; Wu, Y.-L. Tetrahedron Lett. 1996, 37, 893. (b) Gao, Y.; Wu, W.-L.; Wu, Y.-L.; Ye, B.; Zhou, R. Tetrahedron 1998, 54, 12523.

10. Fan, J.-F., $P h D$ Thesis 2000. Shanghai Institute of Organic Chemistry, Chinese Academy of Sciences.

11. Fan, J.-F.; Yin, B.-L.; Zhang, Y.-F.; Wu, Y.-L.; Wu, Y., Ниахие Xuebao 2001, 59, 1756.

12. Yin, B.-L.; Chen, L.; Wu, Y.-L. To be published.

13. Fan, J.-F.; Zhang, Y.-F.; Wu, Y.; Wu, Y.-L. Chinese J. Chem. 2001, 19, 1254.

14. Yin, B.-L.; Gao, Y.; Yang, Z.-M.; Wu, Y.-L. Submitted to ARKIVOC.

15. Yin, B.-L.; Wu, Y.-L. To be published.

16. (a) Huang, Z.-T.; Wang, M.-X. Heterocycles 1994, 37, 1233. (b) Wang, M.-X.; Huang, Z.-T. Prog. Nat. Sci. 2002, 12, 249.

17. Yin, B.-L.; Wu, W.-M.; Fan, J.-F.; Gao, Y.; Wu, Y.-L. To be published.

18. Hofer, O.; Wallnöfer, B.; Widhalm, M.; Greger, H. Liebigs Ann. Chem. 1988, 525.

19. Yin, B.-L.; Wu, Y.-L. To be published

20. Yin, B.-L.; Wu, Y.; Wu, Y.-L., J. Chem. Soc. Perkin Trans. 1 2002, 1746.

21. Yin, B.-L.; Fan, J.-F.; Gao, Y.; Wu, Y.-L. Synlett 2003, in press.

22. Fan, J.-F.; Wu, Y.; Wu, Y.-L., J. Chem. Soc. Perkin Trans. 1 1999, 1189.

23. Yin, B.-L.; Wu, Y.-L. To be published. 